\title{
CARACTERÍSTICAS ARQUITECTÓNICAS DE LAS CONSTRUCCIONES TEXTILES
}

\author{
(TEXTILE STRUCTURES. ARCHITECTURAL CHARACTERISTICS)
}

\author{
Josep I. de Llorens i Duran, y Alfons Soldevila i Barbosa, Drs. Arquitectos \\ Profesores de la Escuela Técnica Superior de Arquitectura de Barcelona. \\ ESPAÑA
}

\section{RESUMEN}

Las construcciones textiles no han sido tratadas

habitualmente como Arquitectura por los manuales de historia o la crítica especializada. La mayor parte de la literatura disponible trata de aspectos técnicos tales como el cálculo o los detalles constructivos. Sin embargo, resultan también esenciales las caracteristicas derivadas de la forma, el espacio que configuran y su relación con el entorno. Para ilustrar estos aspectos, se comentan algunos ejemplos tomados de las experiencias y estudios llevados a cabo por los autores, asi como de las realizaciones existentes. Los principios fundamentales ya se hallaban presentes en los ejemplos más antiguos, como las tiendas de los pueblos nómadas y otras construcciones desarrolladas por la arquitectura popular. La jaima de los Tuaregs y el "envelat" o entoldado catalán muestran planteamientos funcionales adaptados al contexto físico y cultural, resueltos con ayuda de materiales disponibles y tecnologia local.

Otros aspectos observados en ejemplos más recientes, se refieren a forma externa y espacio interior, iluminación y transparencia, estructura y geometría o permeabilidad y transición.

Resulta también relevante la forma de plantear la relación con los edificios próximos como independiente, complementaria, modular-repetitiva o singular.

Estas caracteristicas pueden ser utilizadas para analizar y proyectar construcciones textiles con objeto de controlar la forma resultante y la calidad del espacio interior.

\section{SUMMARY}

Textile structures are not usually dealt with as Architecture in specialised history or critical publications. Most available literature deals with technical aspects only, such as computations or construction details. But other characteristics, as those derived from the shape, the space and the relationship with the surroundings, are also essential.

Some examples taken from experiments and studies conducted by researchers and existing buildings are commented here to illustrate those aspects.

The basic principles were already present in the oldest examples, such as the tents of nomadic people and other construction types developed by folk architecture. The

"Jaima" of the Tuareg and the catalan "envelat" or awning, show functional approaches adapted to the physical and cultural environment and solved with available materials and local technology.

Other aspects noticeable in recent examples are related to the external shape and the inner space, lighting and transparency, structure and geometry or visual permeability and transition. Also relevant is how the relationship with nearby building is approached: as independent,

complementary, modular-repetitive or free standing.

These characteristics can serve as a basis to analyse and design textile constructions in order to control the resulting form and the quality of the interior space.

\section{INTRODUCCIÓN}

Las Historias de la Arquitectura no suelen hacer referencia a la construcción textil. Este tipo de estructuras ha pasado directamente de las soluciones primitivas utilizadas por los pueblos nómadas a las realizaciones de alta tecnologia de los últimos veinte años. Las limitaciones de los materiales disponibles sólo permitian la ejecución de construcciones provisionales y efímeras, que no han sido objeto de análisis por falta de permanencia y durabilidad.

La aparición de materiales sintéticos durables y resistentes y la utilización del ordenador en el análisis de formas complejas, han propiciado recientemente el empleo de este tipo de estructuras con emplazamientos y destinos muy diversos (Figs. 1 a 4).

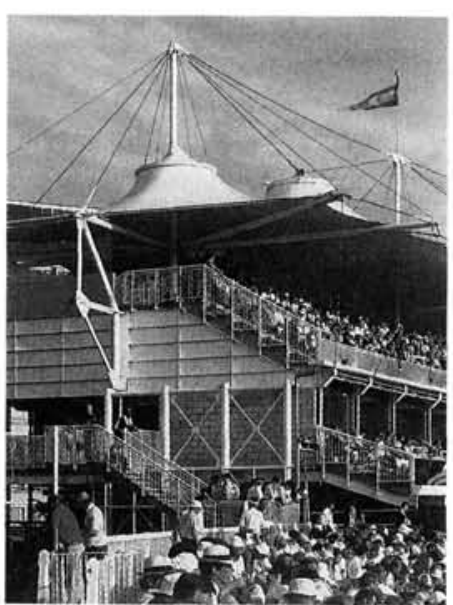

Fig. 1.- M. Hopkins, 1987 Mound Stand, Lord's Cricket Ground, Londres. 


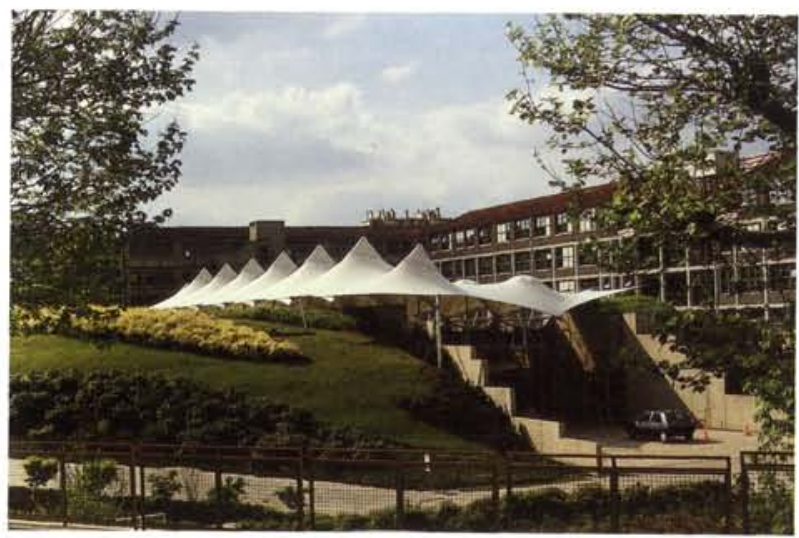

Fig. 2.-R. Piano, 1987. Establecimiento Schlumberger, Les Comptoirs te Montrouge, Paris.
El interés creciente que han motivado se manifiesta en la aparición de bibliografia especializada y la participación en congresos internacionales, en que se presentan las realizaciones más destacadas y los avances más significativos. Sin embargo, la mayor parte del material disponible (mayo, 91) trata preferentemente de aspectos técnicos tales como la descripción de elementos, detalles constructivos, análisis estructural, estudio de la forma, propiedades de los materiales o el modelado con ayuda de ordenador. Por ello se presentan a continuación algunas de las características arquitectónicas de las construcciones textiles que se consideran más interesantes para abordar su análisis, proyecto o realización.

\section{ANTECEDENTES}

\section{El mimetismo de la jaima}

Los pueblos nómadas utilizan todavia varios tipos de tienda fuertemente condicionados por los requerimientos funcionales y la disponibilidad de materiales. De entre todos ellos, destaca especialmente la jaima utilizada por los Tuaregs en el norte de Africa (Fig. 5). Está hecha de lana de oveja o cabra, pelo de camello y madera. Su forma se adapta a las caracteristicas de estos materiales, la climatología, el uso, el entorno y la resistencia estructural. Además, el transporte limita las dimensiones y el peso de los elementos rigidos no desmontables, que se hallan reducidos al minimo y pueden ser manejados con facilidad.

La jaima configura un espacio rectangular único con mástil central. La cubierta y los cerramientos laterales son de una sola pieza de lana, atirantada hacia el perimetro, comprimiendo los palos de borde y formando una superficie continua apoyada sobre puntos, sin travesaños, aristas ni elementos planos. Un capitel de madera evita el punzamiento en el centro. Las costuras se colocan en las lineas de máxima tensión longitudinal y se hallan reforzadas con cintas resistentes que son objeto de decoración.

Es curioso constatar cómo uno de los ejemplares más antiguos de las tiendas disponibles es el más desarrollado desde un punto de vista técnico y funcional. Optimiza los recursos reduciendo al mínimo la estructura. No necesita un esqueleto resistente sobre el que apoyarse, como sucede con el tipi norteamericano 0 la yurta mongol (Figs. 6 y 7 ).

Resiste al viento gracias a la forma, que es una combinación de superficies alabeadas. Además, está atirantada, con lo que evita que se presenten esfuerzos de compresión. La combinación de fibras de lana es resistente a la tracción y acondiciona el espacio http://informesdelaconstruccion.revistas.csic.es 


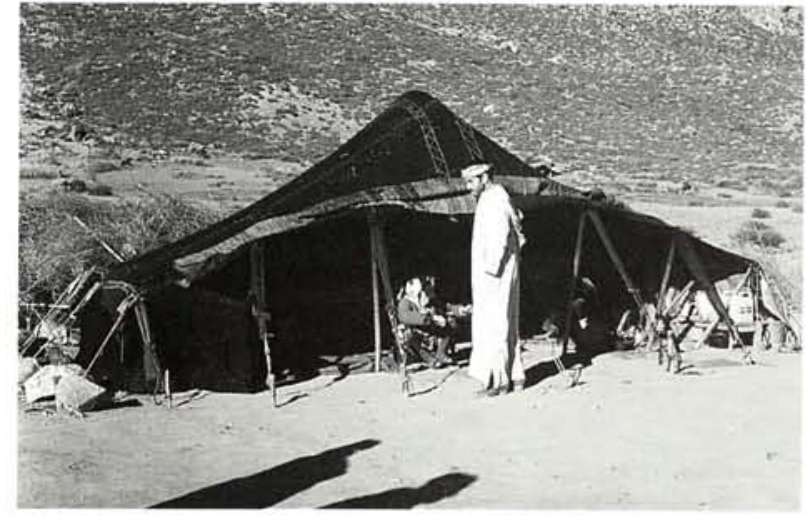

Fig. 5. - La jaima del norte de Africa.

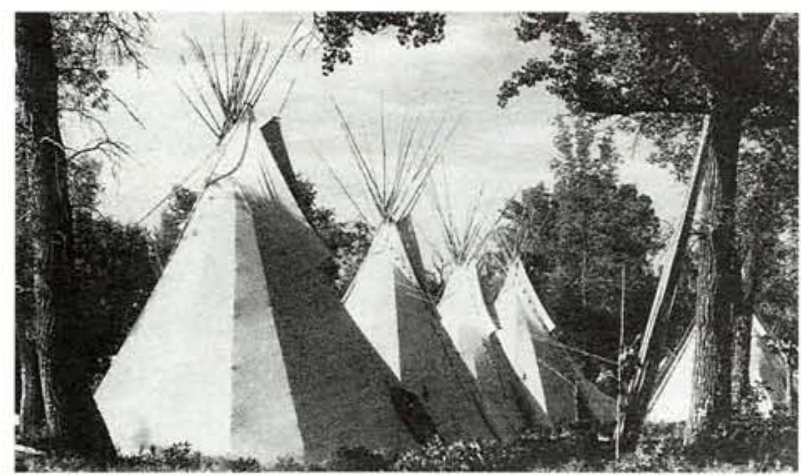

Fig. 6. - El tipi norteamericano (R. \& G. Laubin, OK).

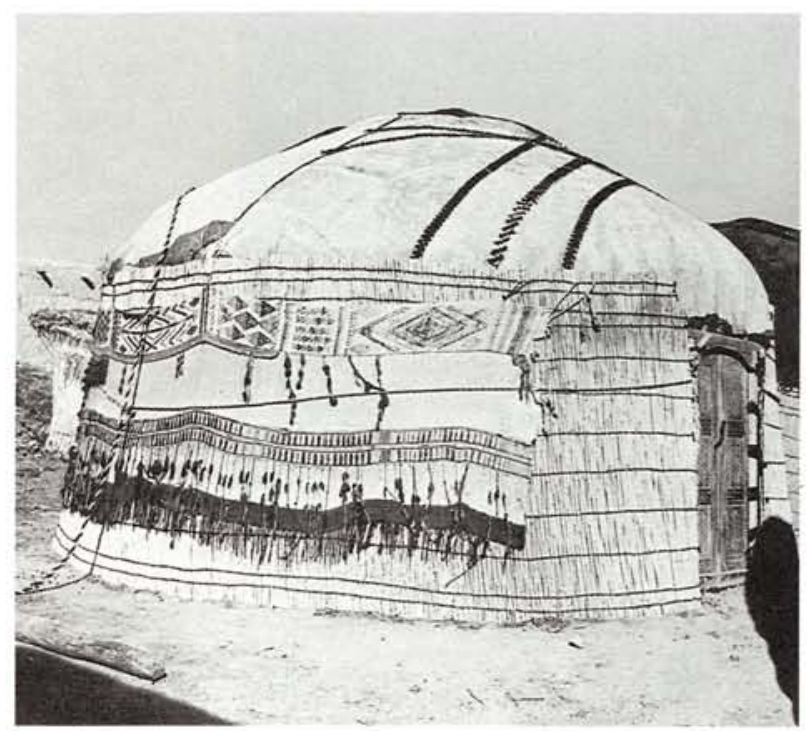

Fig. 7.- La yurta mongol.

(C) Consejo Superior de Investigaciones Científicas Licencia Creative Commons 3.0 España (by-nc)

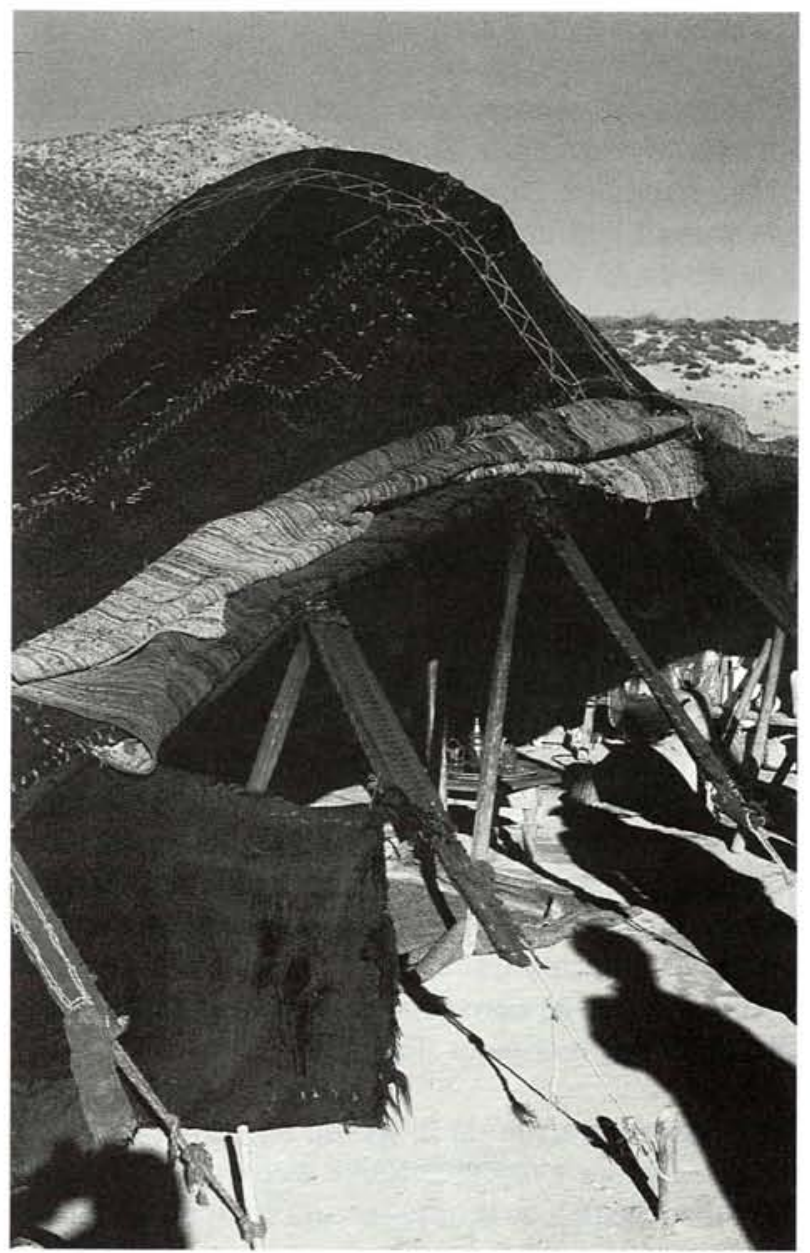

Fig. 8. - La joroba de la jaima.

interior, ya que se contrae bajo el sol abriendo la maila y favoreciendo la ventilación, mientras que se dilata con la humedad y deviene impermeable bajo la lluvia.

La adaptación formal al entorno es casi mimética puesto que el perfil de la cubierta es el mismo que el de la joroba del dromedario, la duna del desierto o del horizonte montañoso (Figs. 8 y 9). No contrapone formas extrañas diferentes a las de la naturaleza circundante.

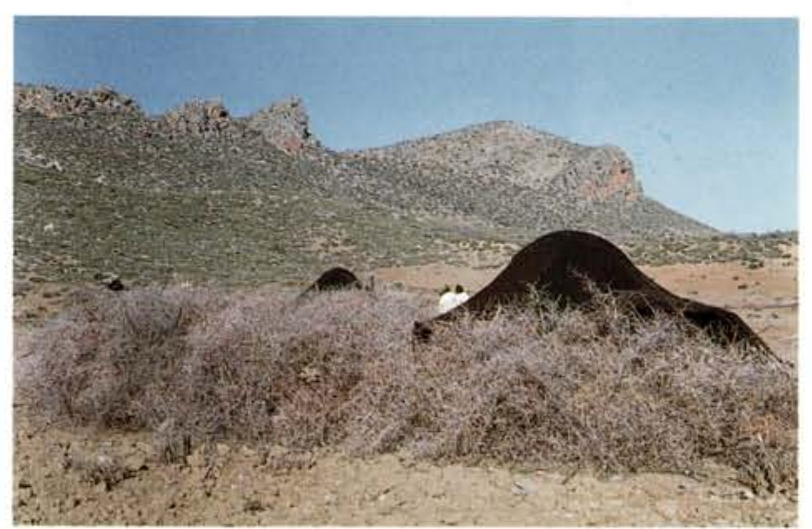

Fig. 9. - La jaima en las estribaciones del Atlas.

http://informesdelaconstruccion.revistas.csic.es 


\section{El simbolismo del Tabernáculo}

El Tabernáculo es la primera construcción especificada por escrito con detalle. Su descripción está contenida en los capitulos 25 a 31 del Exodo. Forma parte del conjunto de instrucciones dadas por Dios a Moisés en el retiro de 40 dias en el monte Sinaí (S. XIII a J.C.) y fue realizado por los artesanos Bezalel y Aholiab.

Era un rectángulo $(15 \times 5 \mathrm{~m})$ de paneles prefabricados de madera arriostrados con vigas transversales del mismo material.

Sobre las vigas descansa una cumbrera longitudinal que sirve de apoyo a la cubierta multicapa de lana y piel. La lana en el interior aisla y ventila, mientras que la piel se encarga del aspecto y la impermeabilidad (Fig. 10). Se trata de la tienda negra beduina (Fig. 11) transformada en santuario desmontable, pero la forma ya no corresponde a la de una construcción textil porque la lona sólo se utiliza para cerramiento y compartimentación. Priman los aspectos representativos porque se intenta adaptar al nomadismo el mítico templo de Jerusalén, símbolo de una sociedad estable y próspera que se conserva en la memoria histórica y que se desea recuperar (Fig. 12).

Esta transformación de la tienda en edificio, de apariencia estable y representativa se halla en el origen de la idea clásica de la arquitectura occidental, puesto que ya desarrolla muchos de sus conceptos fundamentales como son composición geométrica, simetria, ejes, jerarquia y proporción. El espacio interior dividido en dos partes por cuatro columnas y una cortina puede interpretarse como el origen de la división en naos y pronaos del templo griego.

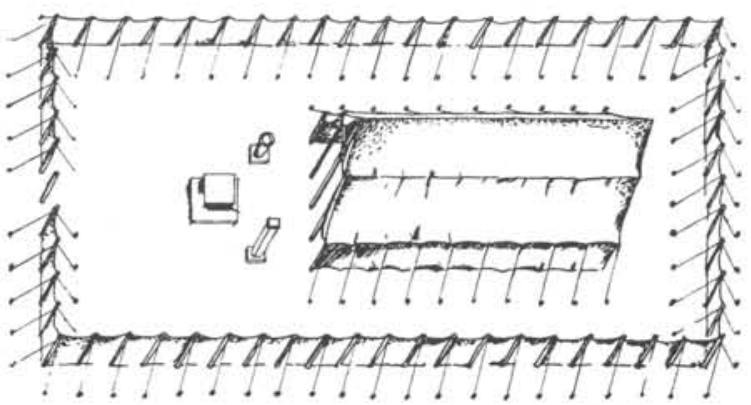

Fig. 10.- El Tabernáculo o templo primitivo segùn Le Corbusier.

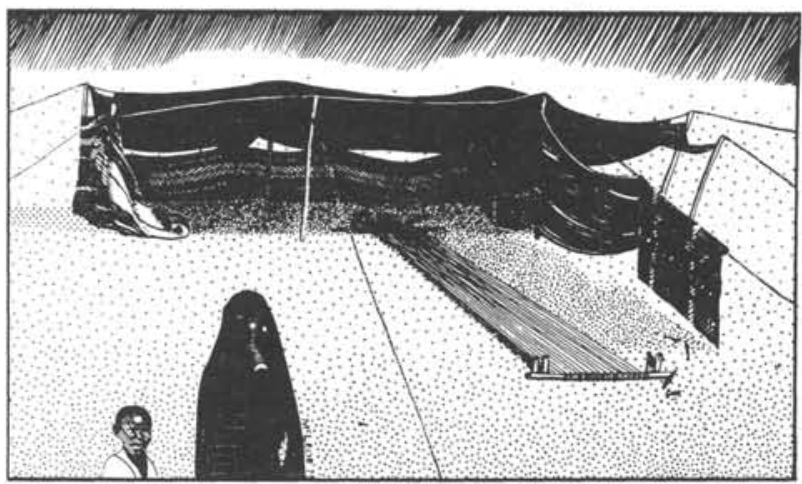

Fig. 11. - La tienda negra beduina (Shelter Publications, CA).

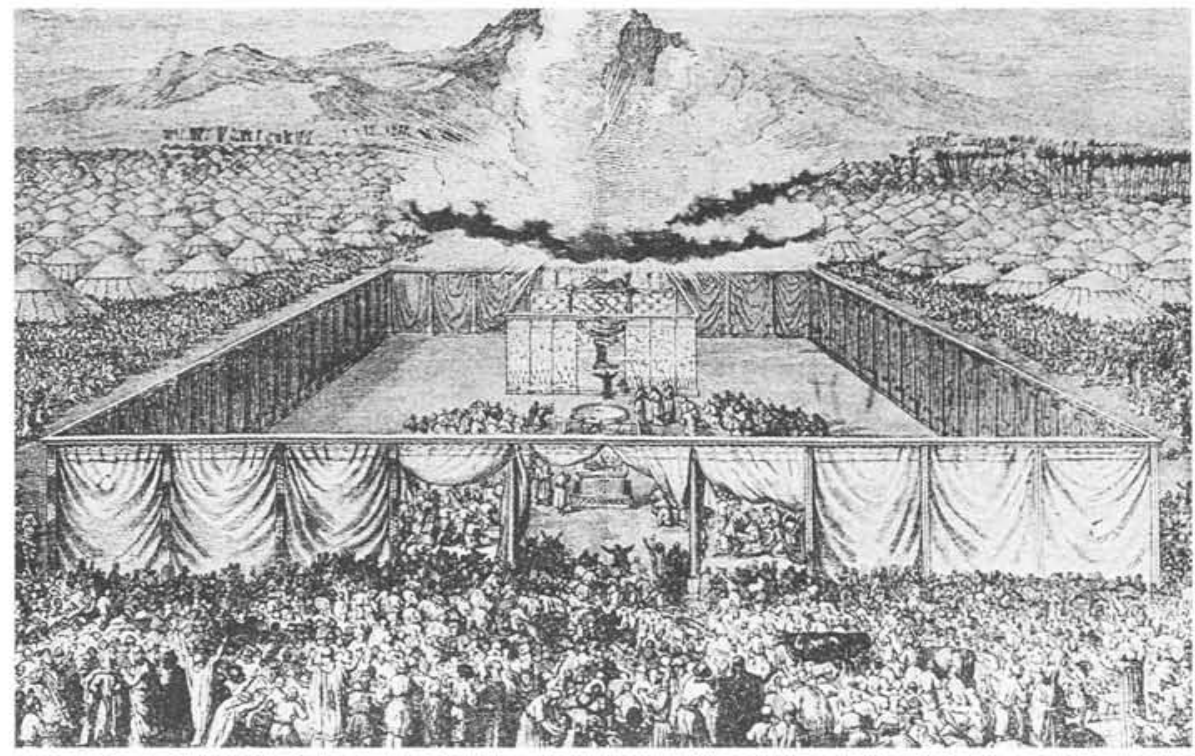

Fig. 12.- Visión idealizada del Tabernảculo. 

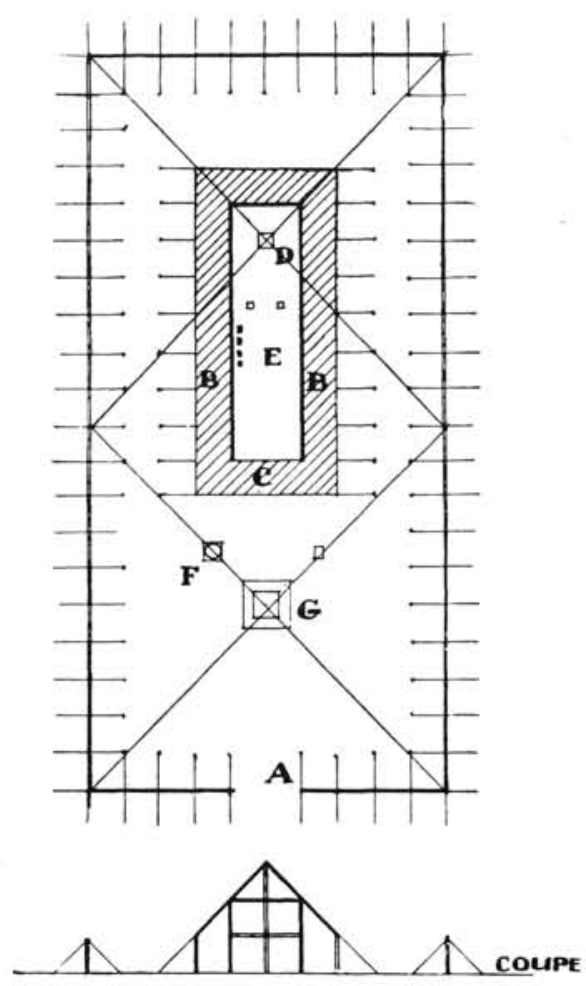

Fig. 13. - Planta y trazado regulador del Tabernáculo (Le Corbusier).
El espacio circundante protegido por las pendientes de la cubierta sería el origen del peristilo y el alzado frontal anuncia el pórtico, aunque varien las proporciones, puesto que las del Tabernáculo corresponden todavia a las de la madera. En ambos casos el uso ha trascendido ya el del refugio artificial primitivo y no alberga al hombre, sino a la divinidad.

Le Corbusier también exploró los orígenes de la arquitectura en el Tabernáculo, al que Ilamó templo primitivo. Observó especialmente la modulación en base al codo $(50 \mathrm{~cm})$, la composición geométrica y el trazado regulador (Fig. 13).

\section{El tamaño del circo}

El circo culmina el proceso de ampliación de las dimensiones de la tienda de campaña (Fig. 14).

Tiene su origen en los espectáculos ambulantes, especialmente el de Bufalo Bill, que alojaba hombres y animales en grandes tiendas y se planteó la protección de los espectadores.

Puede considerarse el paralelo textil de la espaciosidad de la arquitectura del hierro desarrollada durante el siglo XIX, experimentada en las exposiciones universales y aplicada a grandes espacios públicos como mercados, galerias y estaciones de ferrocarril.

En el circo se optimiza el diseño en función de las necesidades de montaje (4 horas) y transporte a distancias cortas y largas. Es una tienda muy grande apoyada sobre mástiles centrales y palos intermedios que acortan las luces y tensan el conjunto.

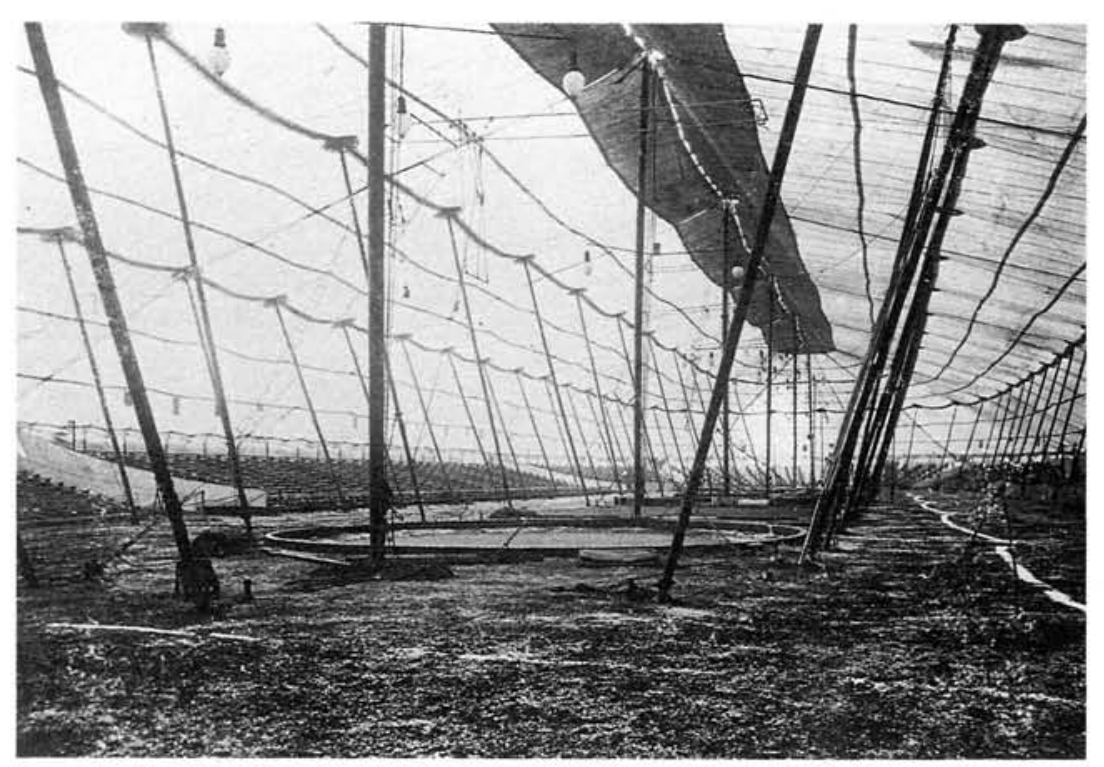

Fig. 14. - El circo Barnum \& Bailey. 


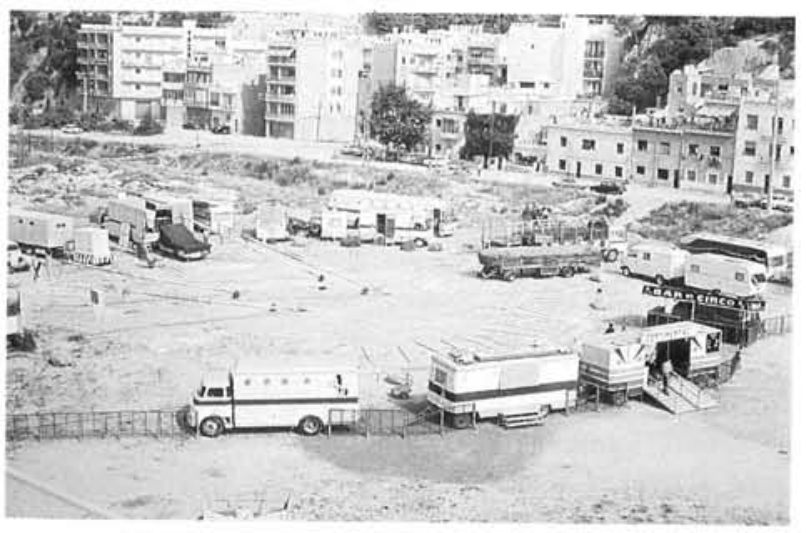

Fig. 15. - Montaje de circo $=1$ Izado de mástiles

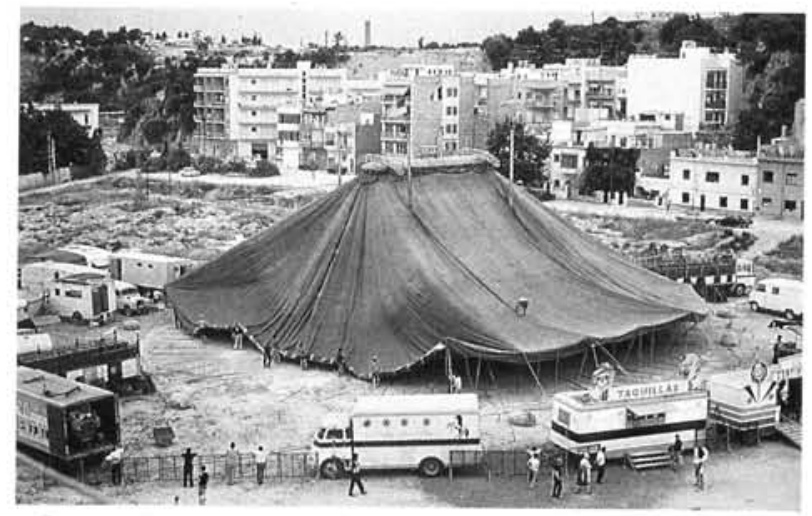

Fig. 17.- 3. Se estira la carpa.

La altura máxima en el centro focaliza el espacio interior hacia la pista o pistas donde se desarrolla el espectáculo.

El volumen exterior es circular y neutro. Por ello se adapta con facilidad a emplazamientos urbanos o espacios abiertos. La caravana del circo colmata los rincones sobrantes. Resultan especialmente interesantes los detalles constructivos relacionados con el montaje tales como las articulaciones, atirantamientos,

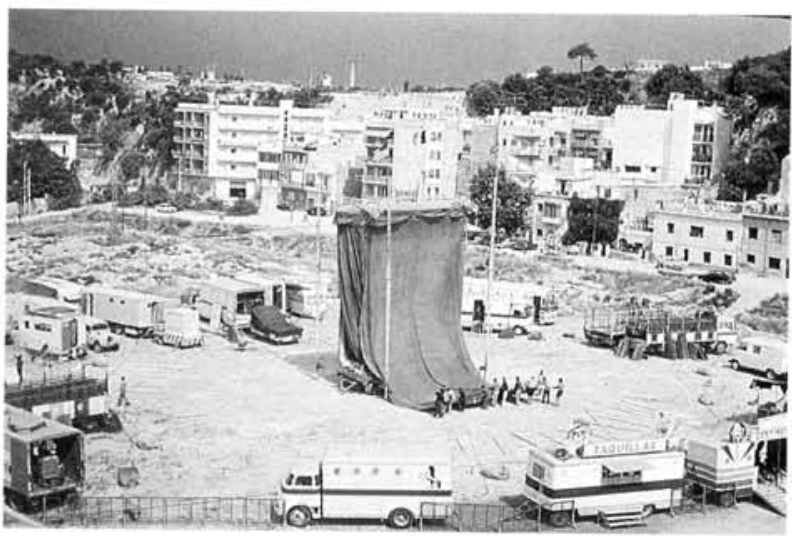

Fig. 16.-2. La carpa cuelga de la cúpula

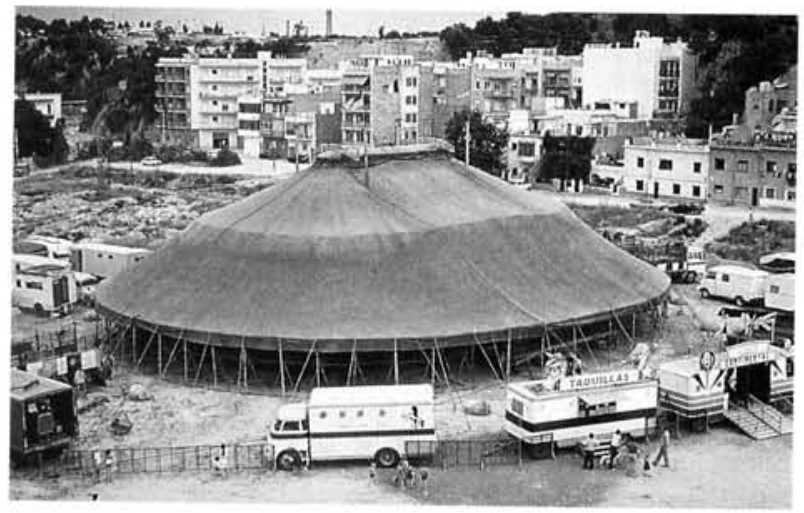

Fig. 18.- 4. Tensado final.

aligeramientos, refuerzos locales, uniones y dispositivos de sujeción (Figs. 15 a 18).

\section{El "envelat": la tienda salón}

El "envelat" o entoldado catalán era una tienda rectangular de grandes dimensiones $(24 \times 36 \mathrm{~m})$ y altura sensiblemente uniforme $(4,5 \mathrm{~m})$ que se utilizaba para celebrar fiestas patronales en la mayor parte de pueblos de Catalunya (Fig. 19).

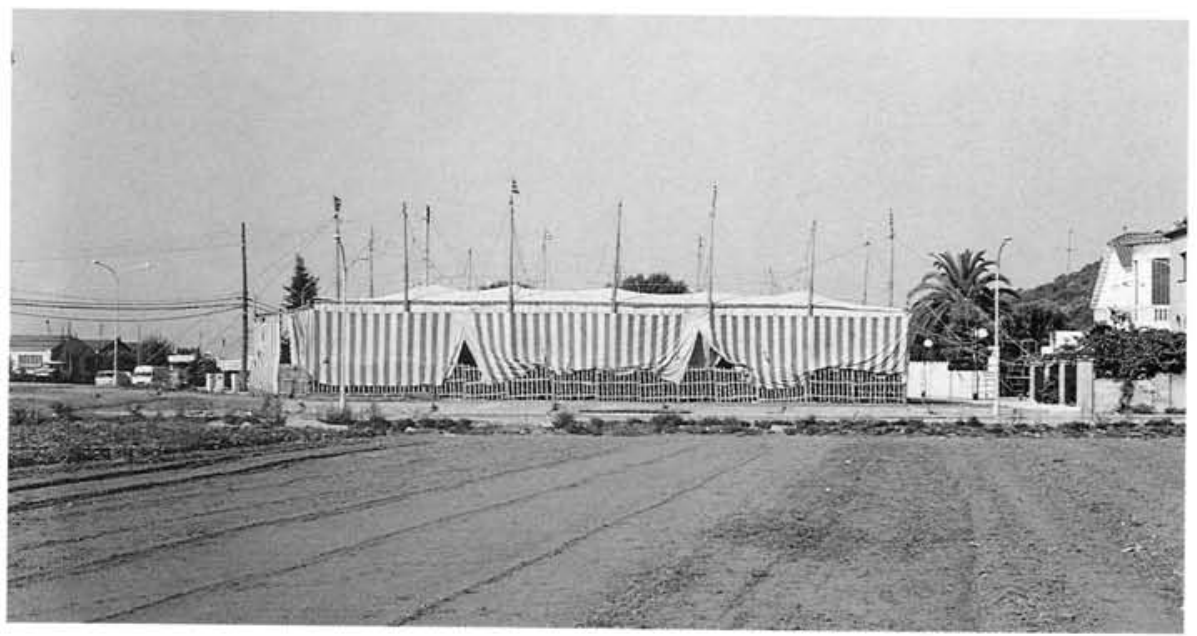

Fig. 19.- El "envelat" de Santa Susana (M. Figueras, 1980). 


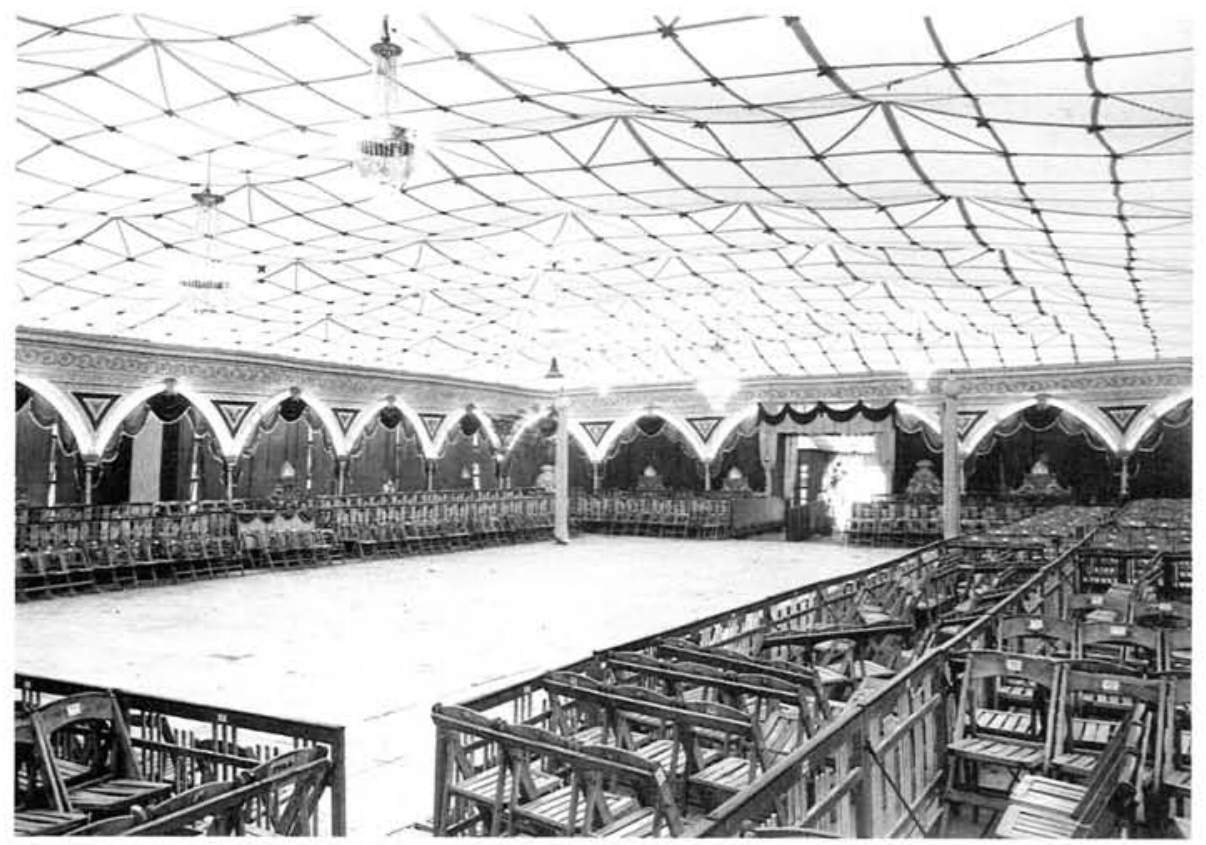

Fig. 20.- El interior del "envelat".

Se trataba de una construcción basada en la tecnologia marinera del Maresme, la región de la costa norte de Barcelona, donde se originó. Consistia en la erección de 80 más pórticos de $24 \mathrm{~m}$ de luz, separados $4 \mathrm{~m}$ entre si y formados por dos mástiles 0 antenas de madera de $9 \mathrm{~m}$ de altura. Las antenas se atirantaban al suelo con vientos y sujetaban la sirga o cuerda principal. Las sirgas llevaban poleas atadas cada $3 \mathrm{~m}$ para pasar las cuerdas secundarias de las que se colgaba la cubierta.

La cubierta o vela era de algodón y estaba formada por elementos de $3 \times 4 \mathrm{~m}$ cosidos entre si. Iban reforzados por cintas cada metro en ambas direcciones formando una retícula que se completaba estampando un motivo decorativo. El cerramiento lateral colgaba de una estructura muy ligera de cabios de madera atados en. tre sí.

El aspecto exterior era el de una caja paralepipédica perfectamente definida y regular. El perimetro se hallaba flanqueado por las antenas verticales de las que colgaba el enjambre de cuerdas estructural.
El espacio interior se distinguia por la diafanidad, puesto que carecia de soportes interiores. Se organizaba alrededor de la pista de baile a la que se adosaba el escenario para albergar la orquesta o la representación. La decoración trataba de reproducir el ambiente de un salón (Fig. 20).

El "envelat" era una invención. No resultaba de la ampliación de la tienda. En lugar de apoyarse sobre la estructura como el circo, colgaba, con lo que se conseguia eliminar los postes interiores y colocar la cubierta casi horizontal.

La integración al entorno se basaba en la utilización de los elementos constructivos de la costa, procedentes de las embarcaciones y carpinteros de ribera (Fig. 21). Desde un punto de vista formal, el perfil horizontal del volumen construido se relacionaba con la cubierta plana de la arquitectura mediterránea y la línea del horizonte (Fig. 22). Por otra parte, la idea espacial de la sala diáfana de grandes dimensiones ha sido un invariante histórico de la arquitectura catalana, como se manifiesta en el espacio central unificador de las masias o la nave única del gótico local.

http://informesdelaconstruccion.revistas.csic.es 


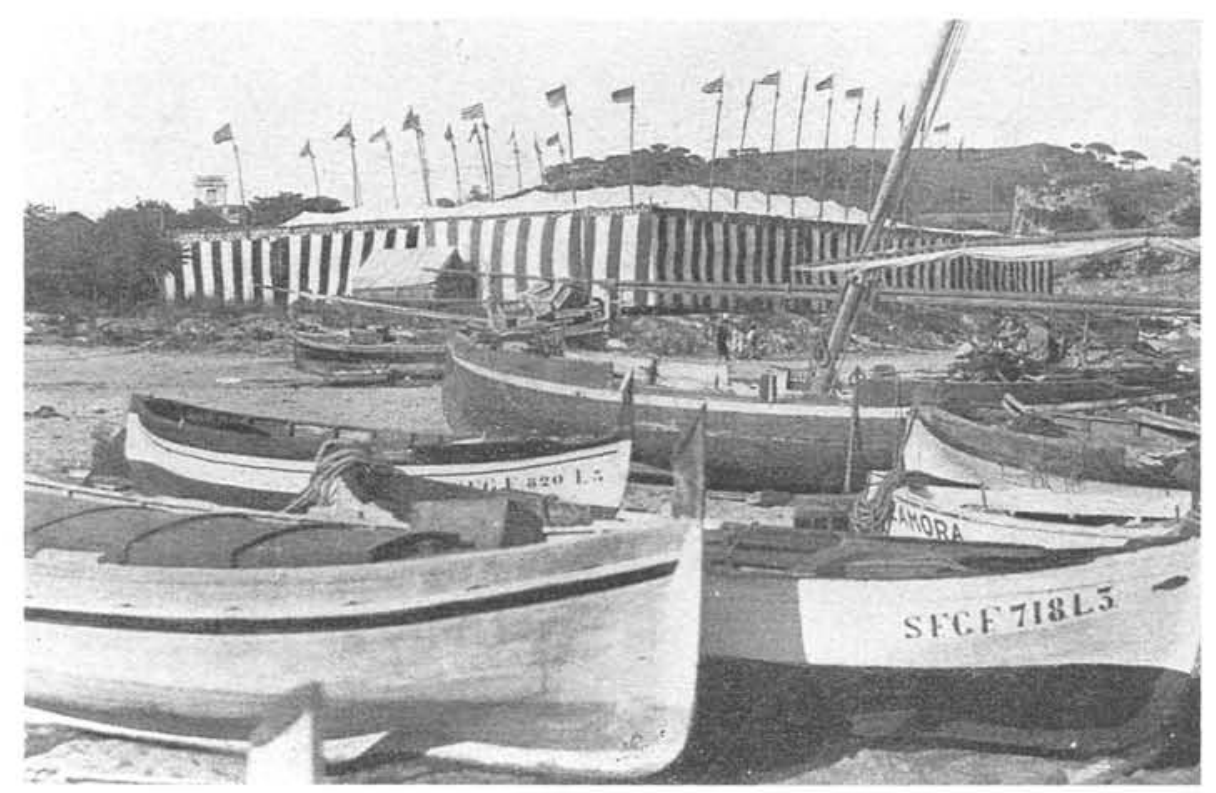

Fig. 21. - El "envelat" utilizaba tecnologia marinera.

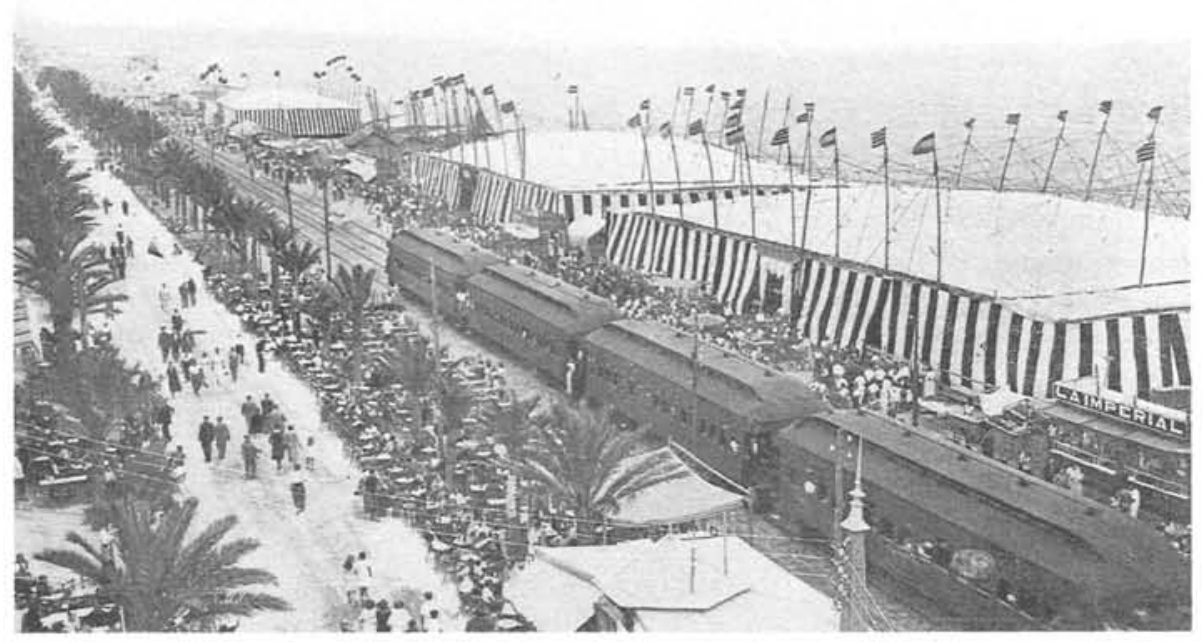

Fig. 22. - Tres "envelats" en la playa de Badalona.

\section{EL ASPECTO EXTERIOR}

El aspecto exterior de las construcciones textiles viene determinado por la singularidad de la superficie que configuran, por lo que suelen destacarse formalmente llamando la atención. Se trata de elementos en los que predomina la cubierta formada por una superficie continua de doble curvatura y muy poco espesor. Actúa a la vez como cerramiento y estructura, con lo que la geometria queda determinada por la función. Se distinguen además de otros tipos constructivos por el uso de materiales y estructuras ligeras que expresan un carácter de provisionalidad 0 , al menos, no tan permanente como la construcción tradicional (Fig. 23). 


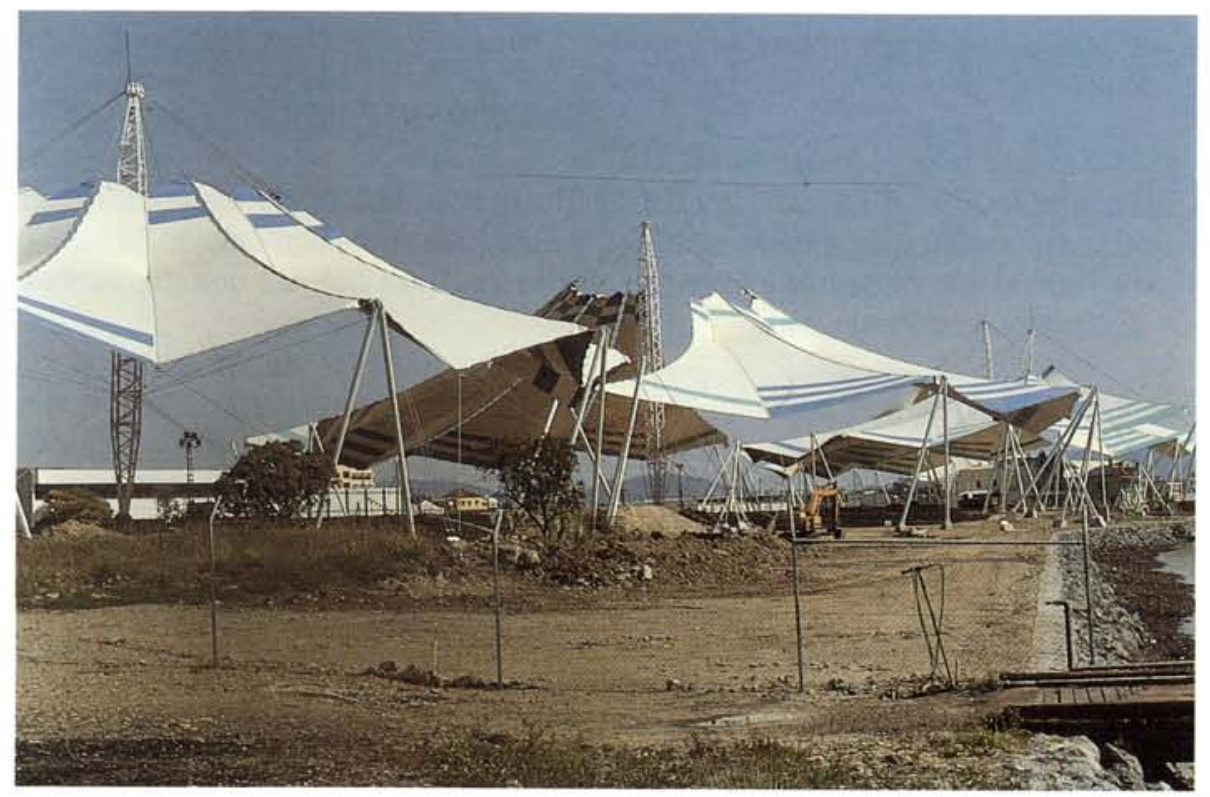

Fig. 23.- R. Roche, D. Sulzer \& H. Muehlberger. Cubiertas para la Expo de Brisbane 88

\section{TRANSICIÓN}

El acceso al interior de las construcciones textiles no se realiza de forma brusca, traspasando un elemento rígido que delimita claramente la entrada como una puerta o un umbral, ya que los bordes de la cubierta determinan un espacio de transición.

La percepción de los límites no es muy precisa, porque el ambiente interior, determinado por la luminosidad de la cubierta, la escasez de aislamiento y la amplitud de las aberturas, contribuye a debilitar la sensación de haberse introducido en un espacio cerrado. Lo cual modifica la situación del usuario, que se halla bajo cubierto sin haber pasado al interior.

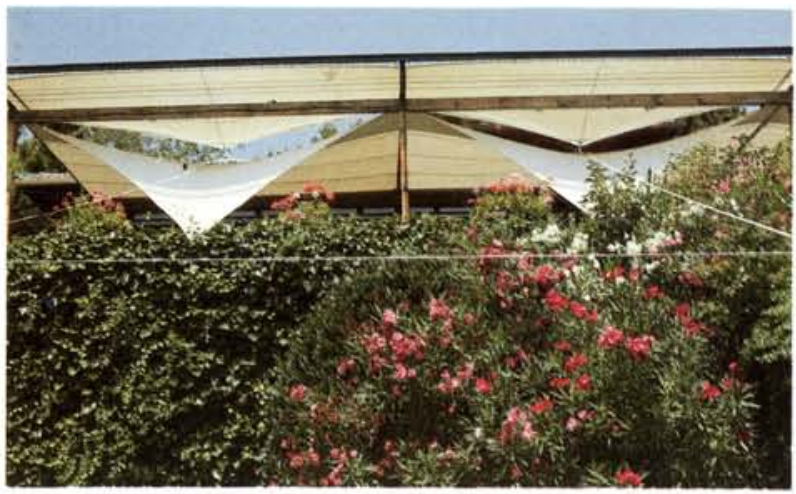

24

(C) Consejo Superior de Investigaciones Científicas Licencia Creative Commons 3.0 España (by-nc)
Figs. 24 a 26. - LL. \& S., 1986. Cubierta para el restaurante "La Balsa" Barcelona.

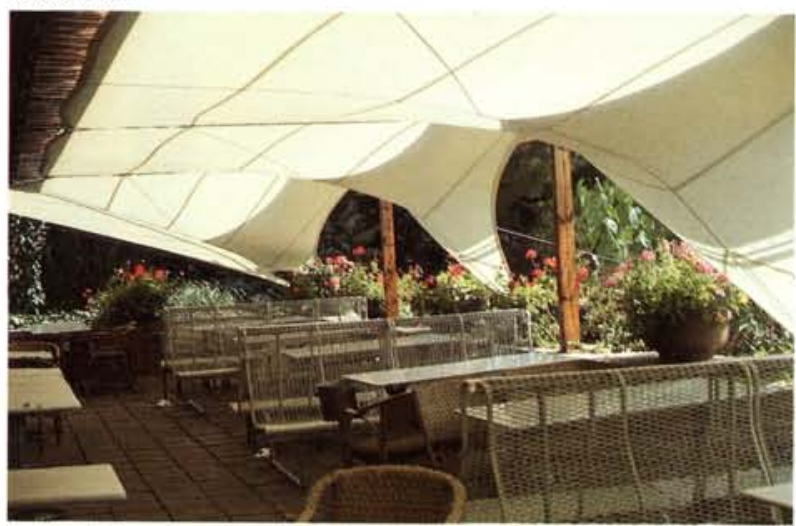

25

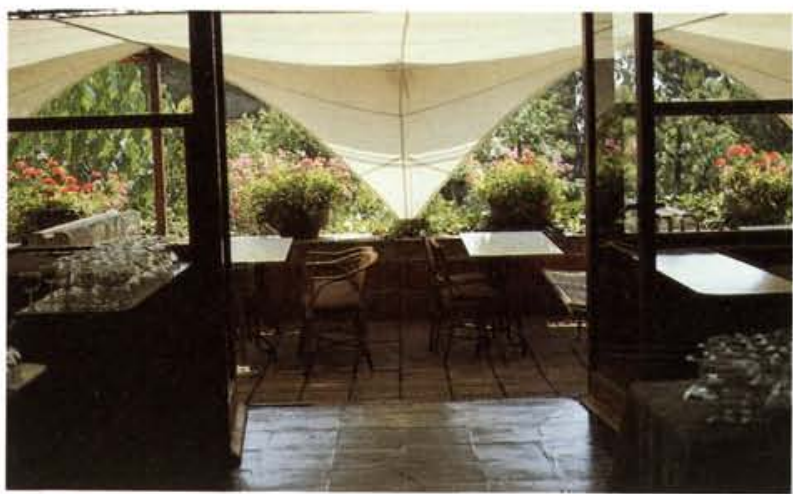


Este aspecto favorece la creación de espacios intermedios muy adecuados en climas benignos, para proyectar los edificios hacia el exterior por medio de filtros ambientales que suavizan la transición ambiental y formal.

Este es el caso de la cubierta para el restaurante "La Balsa" (Clotet \& Tusquets, Arqtos.) (Figs. 24 a 26) que configura un espacio complementario de condiciones intermedias. Actúa de filtro visual y además puede ser utilizado de mayo a octubre como comedor.

Los condicionamientos del proyecto se basaban en la insuficiencia de la altura disponible para desaguar la cubierta y la regularidad del perimetro del edificio, correspondiente al de la balsa original, que se trataba de conservar.

Se resolvió con una sucesión de módulos formados por dos hojas a distinto nivel. En el inferior, la hoja más grande, cubre la mayor parte del espacio y desagua solamente por un punto, con lo que interfiere muy poco con el volumen disponible debajo de la cubierta. La hoja superior completa la superficie a cubrir y recupera la horizontalidad del perimetro.

El conjunto se percibe como un espacio unitario continuo de luminosidad amortiguada, marcado por el

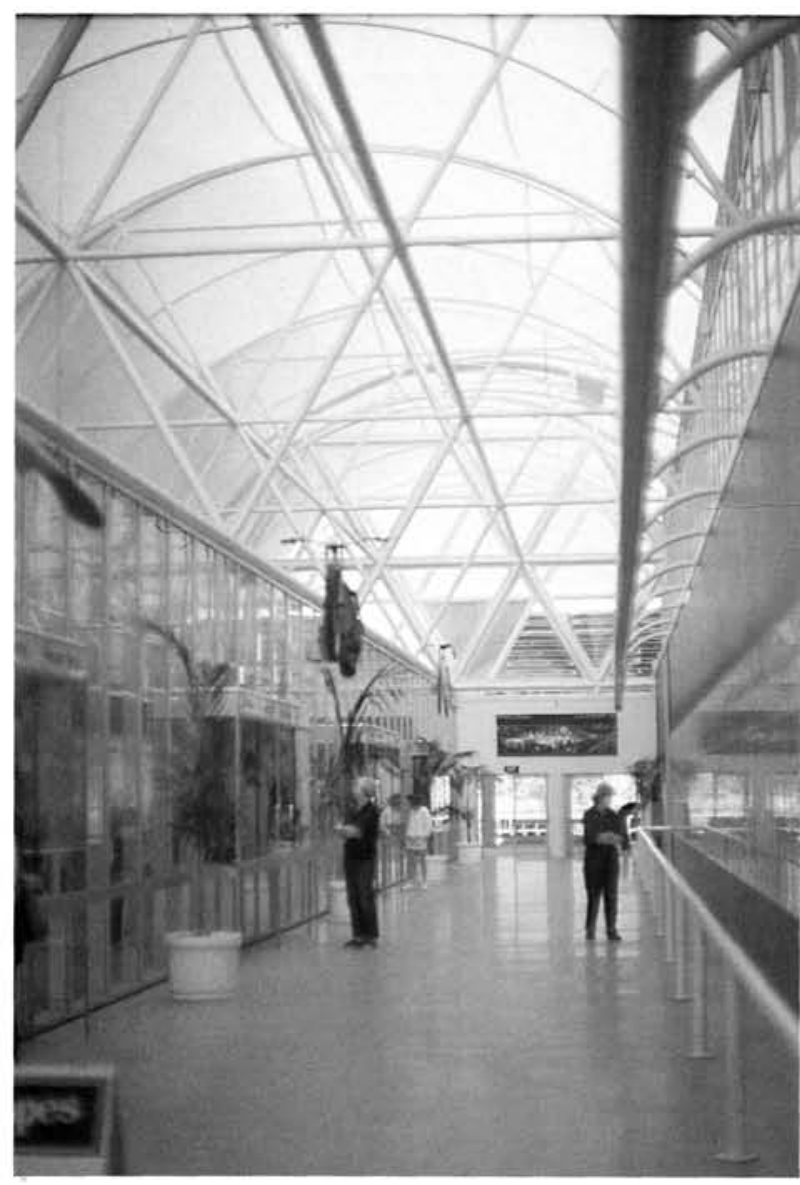

Fig. 27.- Homebush Sports Center. Sydney. ritmo de los módulos, delimitados por la estructura resistente y la forma acusada de la hoja inferior.

\section{ESPACIO INTERIOR}

El espacio interior de las construcciones textiles se caracteriza por la iluminación, la forma y los elementos constructivos que las complementan.

El material con el que se realiza la cubierta suele ser fibra de vidrio o poliéster, revestidos respectivamente con teflon o PVC. En ambos casos, el coeficiente de transmisión de la luz suele ser superior al 10\%, suficiente para prescindir durante el dia de la iluminación artificial. Por ello la cubierta actúa como techo difusor que confiere al espacio una luminosidad general (Fig. 27).

Por otra parte, se producen variaciones y matices según las curvaturas y pendientes que modifican el ángulo de incidencia de la luz.

La lectura de la forma de la cubierta queda reforzada además por las costuras que se marcan al trasluz, orientando las visuales y reflejando de este modo el proceso de ejecución en el resultado final (Fig. 28).

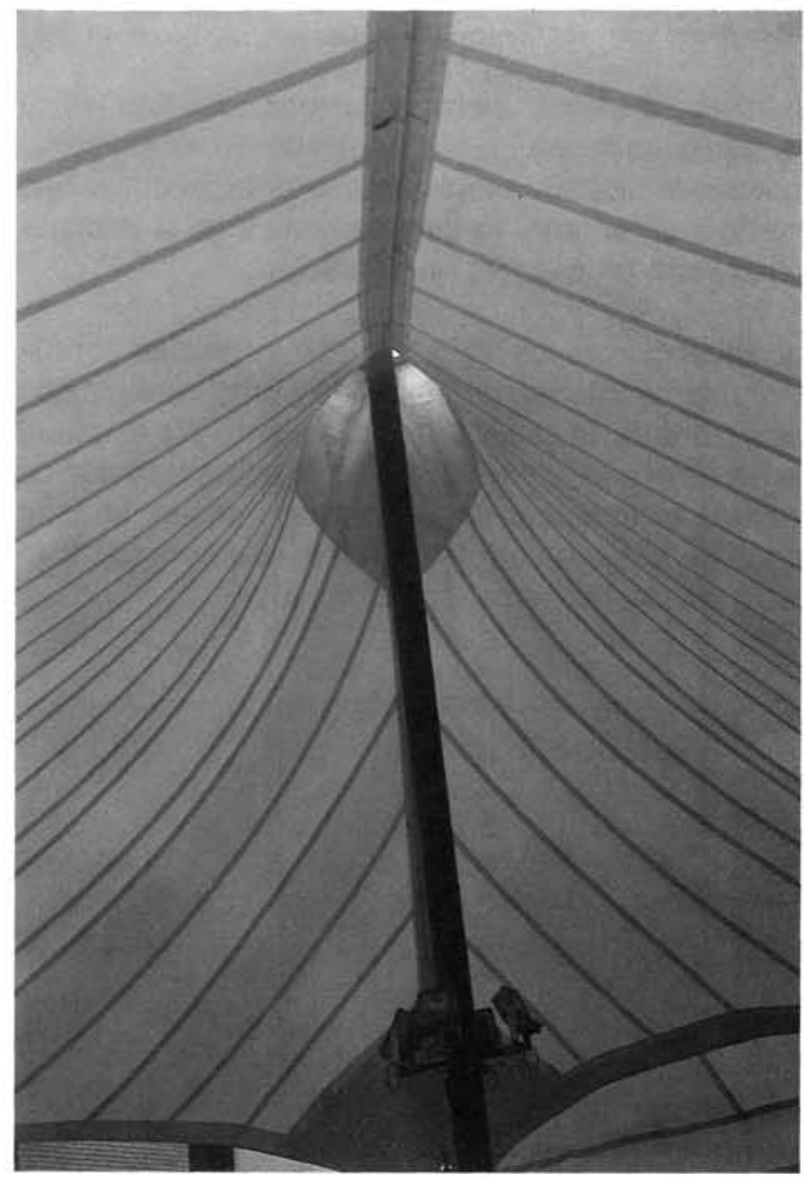

Fig. 28.- New York Aquarium, Boardwalk, Brooklyn, NY. http://informesdelaconstruccion.revistas.csic.es 


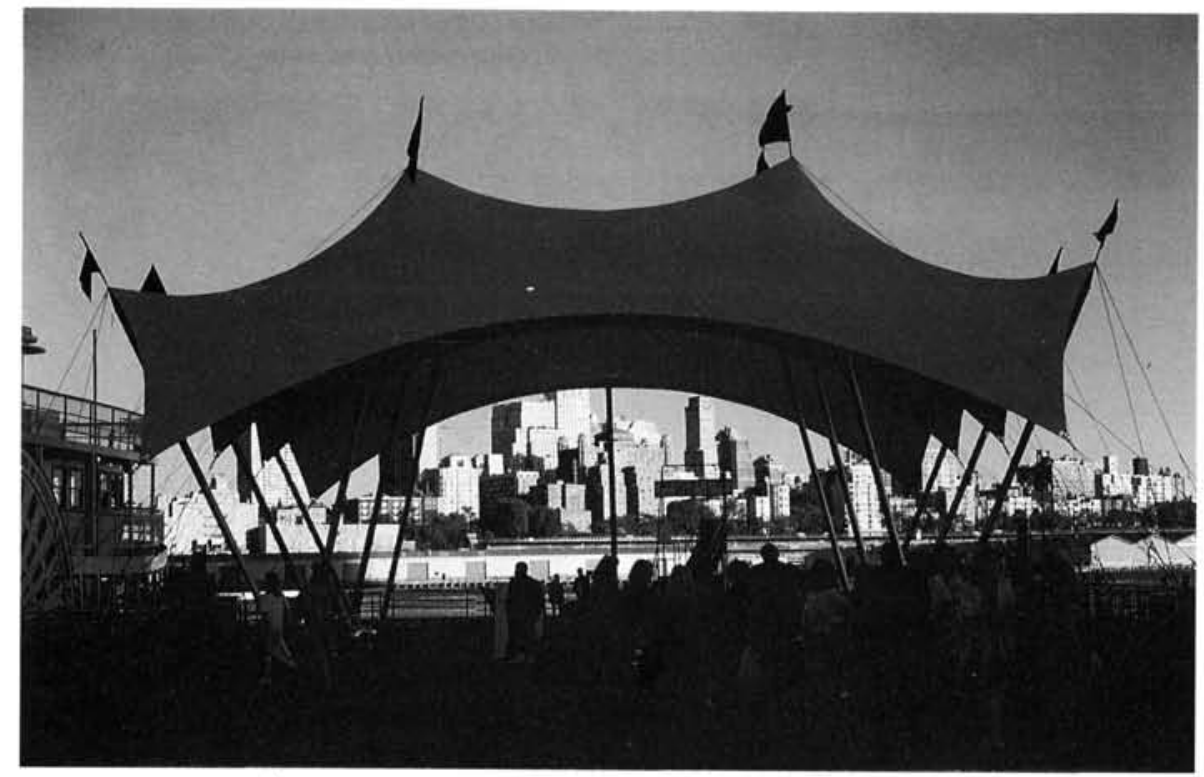

Fig. 29.-Southstreet Seaport Museum, New York.

En la configuración del espacio también intervienen elementos constructivos, tales como: mástiles, arcos, vigas, celosias, desagües, cerramientos y uniones.

Deben ser tenidos muy en cuenta porque pueden desvirtuar y confundir fácilmente las características ya descritas por tamaño, proporciones o incompatibilidad formal.

\section{TRANSPARENCIA VISUAL}

Muchas cubiertas textiles carecen de cerramiento lateral y compartimentación, con lo que no se interrumpe la comunicación visual.

Las vistas hacia el exterior quedan enmarcadas entre el borde de la cubierta y los elementos estructurales, favoreciendo la sensación de distancia y profundidad (Fig. 29).

Estas caracteristicas visuales contribuyen, junto a la luminosidad de la membrana y la suavidad de la curvatura, a enriquecer la calidad del espacio interior.

(c) Consejo Superior de Investigaciones Científicas

Licencia Creative Commons 3.0 España (by-nc)

\section{RELACIÓN CON EL ENTORNO}

\section{Edificios existentes}

Es frecuente que se planteen las construcciones textiles como complementarias a edificios existentes. En este caso, las pre-existencias condicionan considerablemente el diseño de la forma, entrega y elementos estructurales.

En el toldo para el jardin de la casa Olérdola (Bach \& Mora, Arqtos.) se trataba de proteger un espacio definido por el propio edificio y los muros que delimitan el solar. La unión de la lona (flexible) con el muro (rígido) está resuelta mediante un elemento que evita el contacto entre dos materiales tan diferentes. Se trata de una barra separada de la pared que sujeta la lona por medio de ganchos y gomas, formando una celosía transparente, de transición. (Figs. 30, 31 y 32 de la pág. siguiente).

Las costuras atraviesan la cubierta en dirección perpendicular al alzado frontal, reforzando la profundidad de la perspectiva y enfatizando la forma.

http://informesdelaconstruccion.revistas.csic.es 


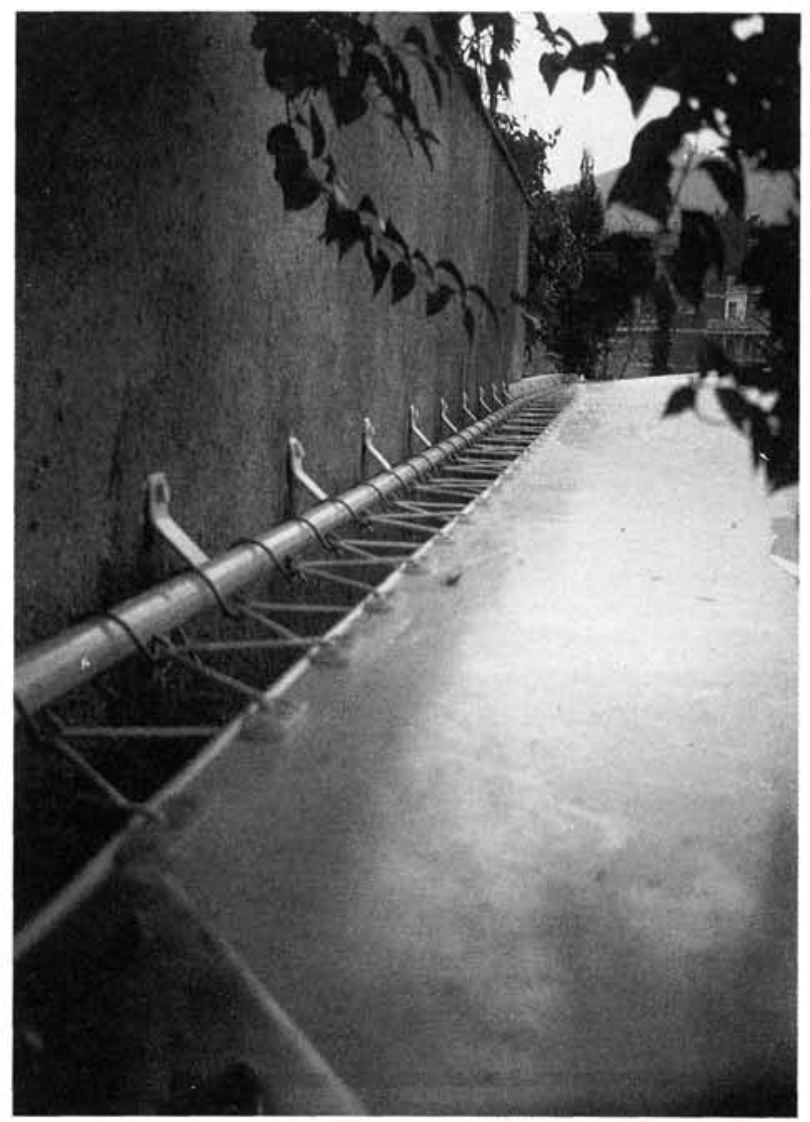

30

Figs. 30 a 32.-D. LL. \& S., 1980. Cubierta para el jardin de la casa Olérdola. Barcelona.

\section{Contexto urbano}

También se plantea a menudo la situación de las construcciones textiles en emplazamientos urbanos, como es el caso de las cubiertas para pistas polideportivas.

Los problemas que presentan la construcción de un polideportivo en ambientes urbanos son de escala y

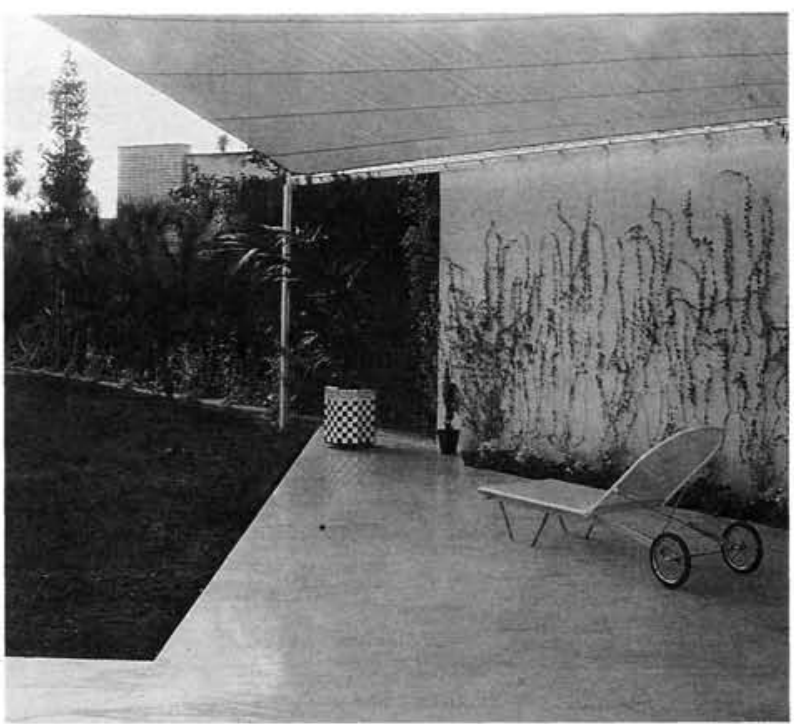

31

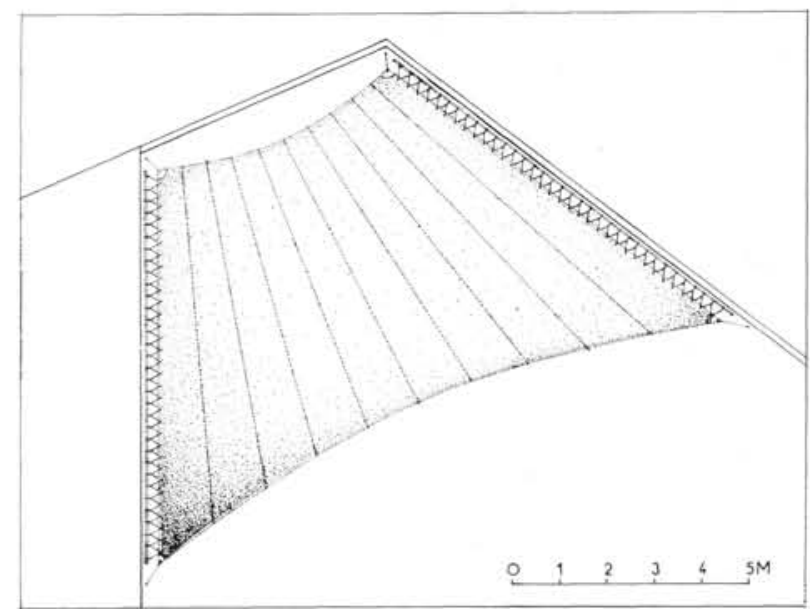

32

continuidad. La desproporción del volumen a edificar puede llegar a competir con la iglesia, castillo, palacio u otros elementos arquitectónicos significativos de la imagen o perfil de la ciudad. Por otra parte, el cerramiento lateral a partir de $7 \mathrm{~m}$ de altura por 30 ó 40 de longitud, representa una interrupción de la continuidad visual que la trama urbana no permite suavizar ni absorber. 


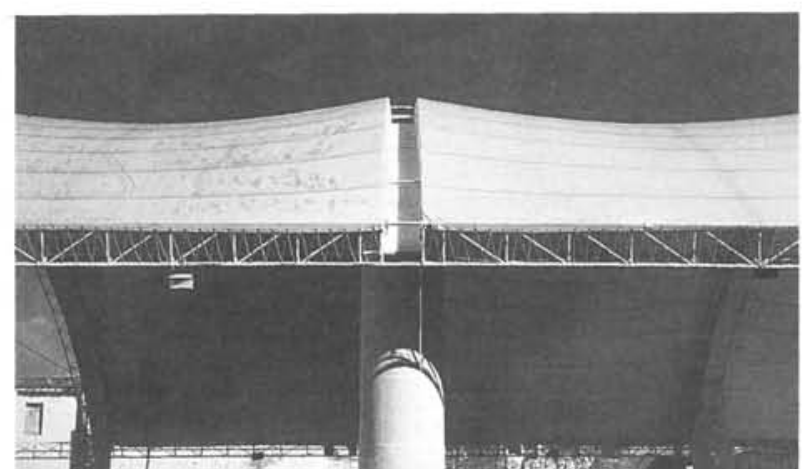

33

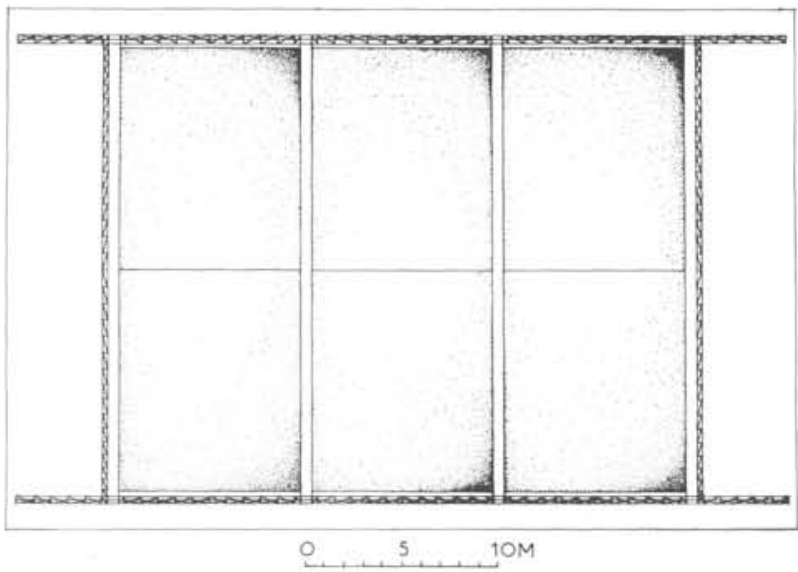

34

Por ello la pista municipal de Rubi se proyectó sin cerramientos laterales (Figs. 33 a 35). Se halla emplazada en el interior de una manzana a remodelar, en el centro de la ciudad. La estructura se resolvió con arcos dobles, estables sin arriostramiento, formando pasarelas para facilitar el mantenimiento, que tiene que

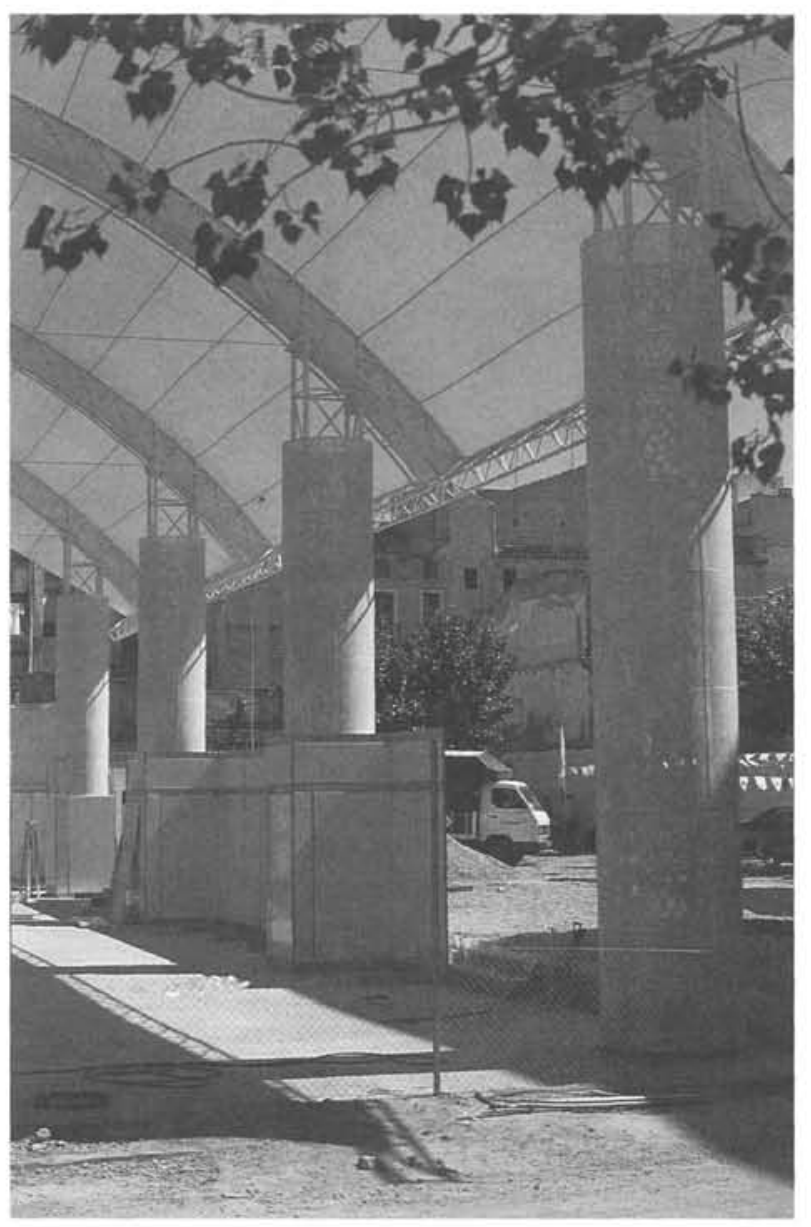

35

Figs. 33 a 35.- LL. \& S., 1986. Pista municipal de Rubi.

ser llevado a cabo por personal no especializado de la brigada municipal. Los pilares en celosía de tubo de acero se forraron con chapa perforada para evitar im. prudencias y proporcionar volumen, con objeto de delimitar de manera discontinua el espacio del recinto. 


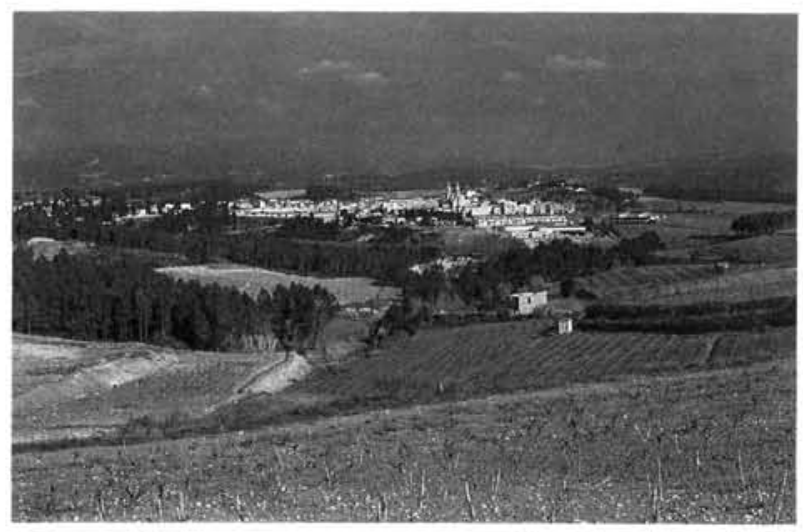

Fig. 36.-Sant Esteve Sesrovires.

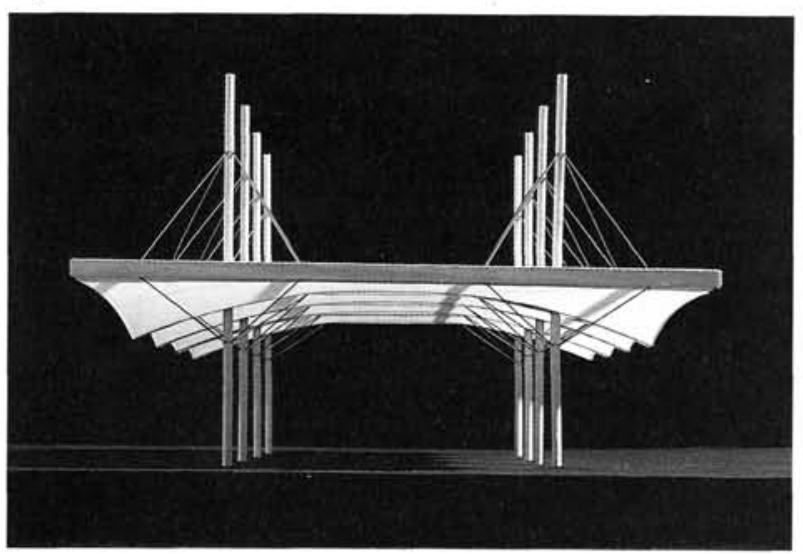

Fig. 37- LL. \& S., 1991. Pista municipal de Sant Esteve Sesrovires.

En la pista municipal de Sant Esteve Sesrovires el problema es similar. Se trata de construir una cubierta de grandes dimensiones muy próxima al centro de un pueblo de baja densidad, cuyo volumen más significativo es la iglesia (Fig. 36).

También se ha optado por prescindir de los cerramientos laterales para evitar planos verticales. La estructura consta de 4 módulos formados por dos vigas atirantadas y un arco apoyado sobre pilares. Las vigas definen el plano de la cubierta, mientras que los arcos generan la doble curvatura, favorecen el desagüe y enmarcan el espacio interior (Fig. 37).

Completan el conjunto las riostras comprimidas y los tirantes traccionados, que aligeran la estructura reduciendo las luces y resistiendo la succión.

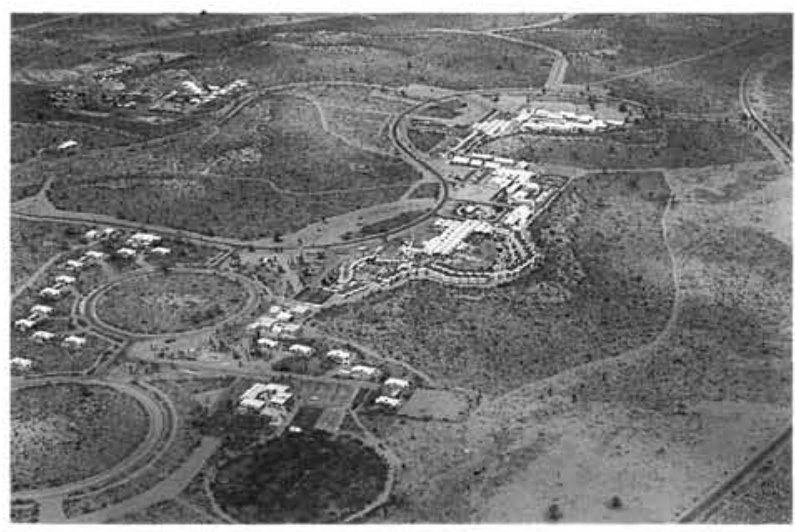

38

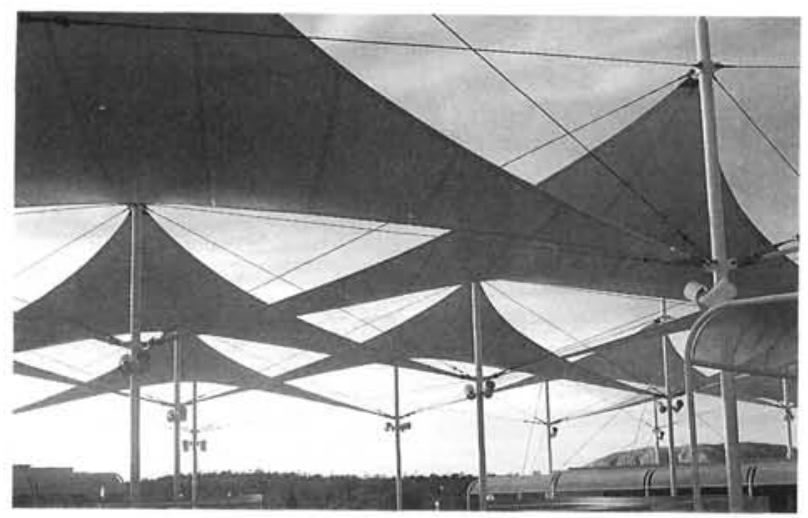

Figs. 38 y 39.- Ph Cox \& O. Arup, 1984. Yulara Tourist Resort, Ayers Rock. Australia.

La cubierta está dividida en 8 partes para facilitar el montaje y el mantenimiento. Es de lona blanca de fibra de poliester forrado con PVC, translúcida e impermeable. Al tratarse de un material estructural permite prescindir de las correas, con lo que se disminuye considerablemente la cantidad de acero estructural.

\section{El entorno natural}

En algunos casos no es necesario tener en cuenta la pre-existencia de elementos arquitectónicos o urbanos, porque no se consideran relevantes o se construye en ambiente natural.

Es el caso del área de información y exposición del parque nacional de Yulara (Figs. 38 y 39).

http://informesdelaconstruccion.revistas.csic.es 
Se trataba de crear un ambiente receptivo con objeto de atraer al turismo hacia el centro de una llanura semidesértica ilimitada y sometida a condiciones climáticas extremas, se optó por repetir un módulo en forma de paraboloide hiperbólico, cubriendo parcialmente el área tratada y proporcionando sombra, sin interrumpir la visión hacia el cielo y el paisaje próximos que son los principales atractivos a conservar. La repetición del módulo y la distribución rítmica de pilares proporcionan orden y medida a la inmensidad del entorno circundante al que contribuyen a domesticar, como las rejas tranquilizadoras que separan la fiera del espectador.

\section{Las cubiertas singulares}

En algunos casos el proyecto se plantea con independencia del entorno. El emplazamiento influye poco en la solución, que atiende más a los requerimientos funcionales y de singularidad.

Éste fue el planteamiento de la cubierta para el escenario al aire libre de la discoteca Bananas (Figs. 40 y 41). Se trata de un recinto cuadrado cubierto con 4 arcos en celosia inclinados, que se arriostran entre si. Una viga de celosia longitudinal en la cumbrera facilita el desagüe, delimitando la divisoria entre las dos pendientes, que llegarían a confundirse, ya que los arcos inclinados configuran una sección transversal de la cubierta muy rebajada en comparación al medio punto del arco vertical.

El atirantamiento se realiza uniformemente a lo largo de todo el perimetro mediante goma blanca elástica continua. De este modo se reparte la tensión, con lo que se evita la concentración de esfuerzos y se facilita el montaje manual, ya que resulta más cómodo estirar poco en muchos puntos si el personal no está especializado y no dispone de medios adecuados.

\section{Prototipos modulares}

Las construcciones textiles son muy adecuadas para realizar estructuras modulares repetitivas que se instalan provisionalmente en emplazamientos de todo tipo. Es el caso, entre otros, de ferias, exposiciones, mercados, bares, restaurantes y establecimientos al aire libre en general.

(c) Consejo Superior de Investigaciones Científicas Licencia Creative Commons 3.0 España (by-nc)

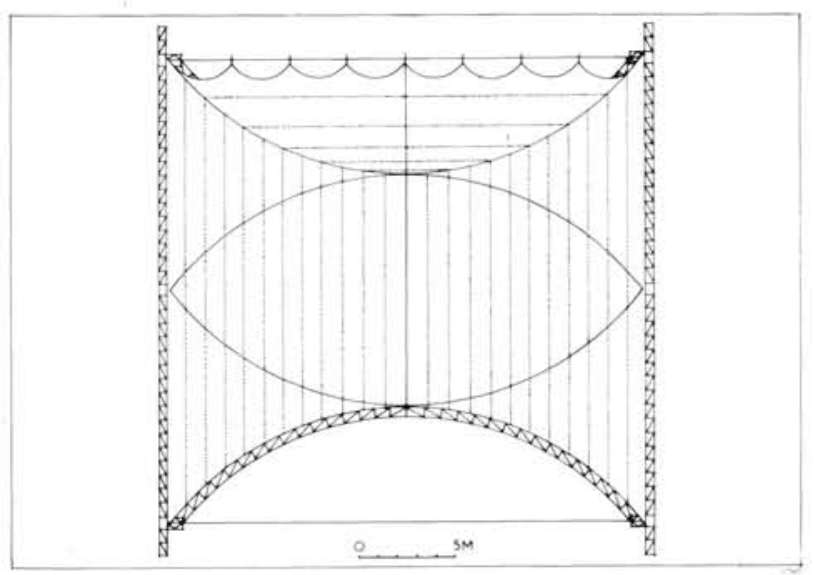

40

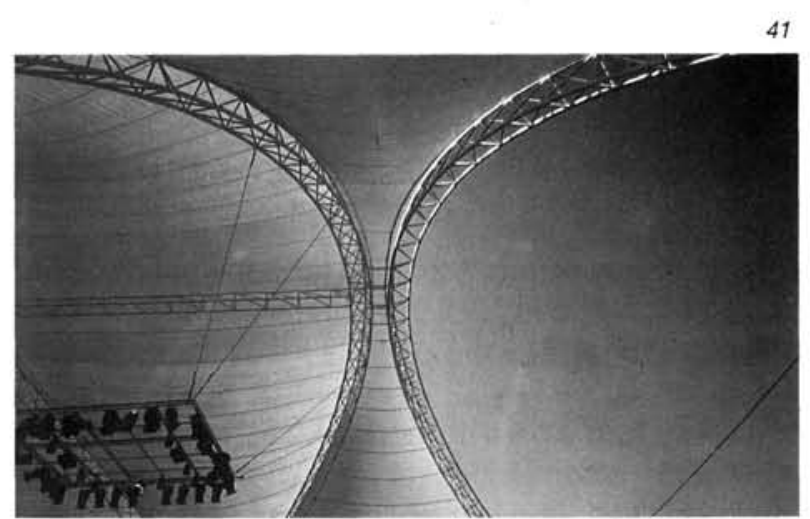

Figs. 40 y 41.- LL. \& S., 1985. Discoteca Bananas. El Bruc.

Requieren autonomia, poco peso y modularidad. La ligereza es requerida para facilitar el transporte y las operaciones de colocación.

La autonomía es necesaria dada la diversidad de emplazamientos a utilizar. La modularidad permite adaptarse a superficies diferentes de acuerdo con el espacio disponible o las funciones a albergar.

Para la ciudad de Lérida se estudió un módulo de toldo para terraza de bares y restaurantes que se adaptara a emplazamientos urbanos de calidad (Fig. 42). Se intentó proporcionar una superficie de cubierta suficiente $(6 \times 4 \mathrm{~m})$, que se pudiera combinar y que se integrase lo más discretamente posible a la complejidad formal del centro de la ciudad. 


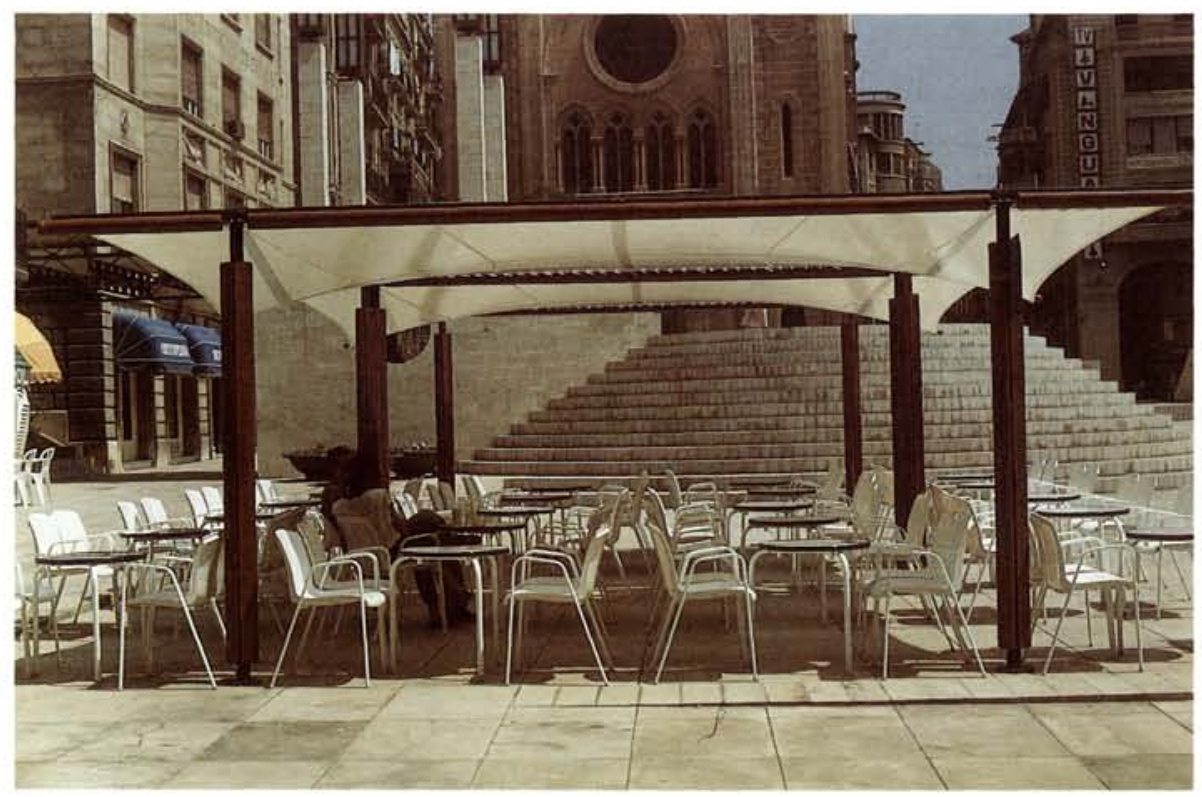

Fig. 42.- LL. \& S., 1987. Modelo Lleida (IASO)

El modelo que se proyectó está formado por dos pórticos principales que mediante travesaños sujetan un arco longitudinal. La lona se ata a los pórticos. El arco, empujándola hacia abajo, la tensa, le da curvatura resistente y forma para desaguar. La estructura se forra con piezas redondeadas de madera para incrementar la receptividad visual y táctil de los perfiles, aumentando la temperatura del metal y disimulando la agresividad de los cantos.

La forma de la cubierta es un plano horizontal deformado por el arco. No aparecen planos inclinados continuos ni elementos verticales que obstruyan la visión. Tampoco se consolida volumen, como sucede con los elementos a dos o cuatro aguas que aparecen como casetas independientes y se destacan desde un punto de vista formal.

\section{CONCLUSIONES}

El análisis arquitectónico de las construcciones textiles pone de manifiesto las siguientes caracteristicas:

- El aspecto exterior queda definido por la superficie, el color, el material utilizado y la forma global.
- Destaca la ligereza del conjunto, tanto de los elementos constructivos como de los materiales que los componen.

- La entrada se produce gradualmente a través del perímetro que configura un espacio de transición.

- La iluminación resulta generalizada, difusa y variable, matizada por la geometria de la superficie y enfatizada por las costuras que se marcan al trasluz.

- Los elementos estructurales intervienen en la configuración general.

- Las vistas quedan enmarcadas y no se interrumpe la continuidad visual.

- Se integran en el entorno completando edificios existentes o adaptando la forma al contexto urbano o natural.

- Las soluciones independientes tienden a la modularidad para adaptarse fácilmente a superficies y emplazamientos diversos.

La lista de caracteristicas arquitectónicas puede ampliarse para describir, analizar y valorar los proyectos de construcciones textiles 0 las realizaciones existentes.

\section{ABREVIATURAS}

D. LL. \& S. = Donada, Llorens \& Soldevila, Arqtos. LL. \& S. = Llorens \& Soldevila, Arqtos. http://informesdelaconstruccion.revistas.csic.es 


\section{BIBLIOGRAFIA}

"Architectures textiles. Structures gonflables", 1975, Techniques \& ARCHITECTURE, mayo-junio. N. ${ }^{\circ} 304$.

Architen Ltd, 1987 "Membrane Structures off the-peg" A J. 11/02/87. pp 63-65

$\mathrm{H}$. Berger, 1989 "New developments in lightweight dome structures" Bulletin of the International Association for Shell and Spatial Structures, Vol-30 N. ${ }^{\circ}$ 101, Nov., pg. 135-145.

G. Cataldi, 1986 "All'origene dell'abitare", Alinea Editrice, Firenze.

A. Cirici, 1972 "Els envelats" Serra d'Or, AÑO XIV, N. ${ }^{\circ}$ 159, dic., pp 92-97.

Committee on the use of tensioned fabric structures by federal agencies, 1985. "Architectural fabric Structures" National Academy Press, Washington D.C.

Le Corbusier, 1923 "Vers une Architecture", Editions Crès et Cie, Paris.

C. Davies, 1985 "Fabric Structures" RIBA Journal, oct., pp. 31-35.

Ph Drew, 1979. "Tensile architecture". Granada publishing Limited. London.

M. Eeckhout, 1989 "Architecture in Space Structures". Vitgeverij 010 Publishers, Rotterdam.

F. Escrig \& J. Pérez Valcárcel, 1989/90. "Conceptos básicos para el diseño y análisis de estructuras ligeras tensadas" Revista de Edificación, N. ${ }^{\circ} 6$, junio $89 \mathrm{pp}$. $40-54$ y N. ${ }^{\circ} 8$, dic. 90 pp 9-24.

T. Faegre, 1979. "Tent, architecture of the nomads". John Murray, London.

Ch. Ph. Fox. 1959. "A ticket to the circus", Bramhall House, New Tork.

S. Groak, 1985. "Schlumberger Research Ltd. Cambridge" A J. 18/19/85. pp 43-59.

E. Guidoni. 1975. "Architettura primitiva", Electa Editrice, Milano.

E. M. Hatton, 1979. "The tent book", Houghton Miffin Company, Boston.
B. Haward, 1984. "Hopkins at Cambridge" A J., 01/02/84. pp 40-57.

S. Heck, 1985. "Piano's entente cordiale". RIBA Jurnal, nov. pp 18-25.

R. Kent, 1985 "The Tabernacle" RIBA, Journal, mayo, pp 20-22.

J. Llorens \& A. Soldevila, 1985. "Construcciones de 10na". ON Diseño. N. ${ }^{\circ} 62$, pp 11-32.

M. Majowiecki, 1985 "Tensostrutture = progetto $\mathrm{e}$ verifica" CISIA, Milano.

J. Monjo, 1985 "La arquitectura textil" Informes de la Construcción", vol.-36, N. ${ }^{\circ} 367$, enero/feb. pp 5-30.

J. Murcia, 1990. "Las estructuras a tracción y sus materiales". Hormigón y acero $\mathrm{N}^{0} 174$, 1er. trim. pp 121-133.

E. Nácar \& A. Colunga, 1964. "Sagrada Biblia". Biblioteca de Autores Cristianos. La Editorial Católica S.A. Madrid.

M. Pawley. 1990 "Store Street Snowline" A R. No 115, enero. pp 40-46.

J.M. Prada, 1986 "Carpa para auditorio en Pinar del Rey, Madrid" Informes de la construcción, Vol. $38, \mathrm{~N}^{\circ}{ }^{\circ} 380$, mayo, pp 39-45.

J.M. Prada, 1989. "El parasol de la lluvia. Cubierta para el palenque" $A \& V$. $N^{\circ} 20$, pp 46-48.

Proceedings of the "First international conference on lightweight Structures in architecture". 1986, Unisearch Limited, the University of New South Wales, Sydney.

C. Roland, 1965. "Frei Otto. Spannweiten". Verlag Ullstein Gmbh, Frankfurt.

J. Schalich, R. Bergermann \& W. Sobek. 1990 "Tensile membrane Structures". Bulletin of the International Association for Shell and Spatial Structures. Vol. $31 \mathrm{~N}^{\circ}$ 102-103 pp 19-32.

V. Sedlak. 1985 "Membrane Structures" RIBA Jurnal marzo, pp 21-33.

E. M. Viollet le Duc, 1875. "Histoire de I'habitation humaine", Bibliothéque d'èducation et de récréation. Paris.

J. Winter, 1987 "Mound Stand Lord's cricket ground, London" J A 02/09/87. pp 38-54. 